\title{
Author Index
}

Ambrosio, A. 101

Bevans, S.E. 132, 145

Boseley, M. 145

Brigger, M.T. 101, 137

Bruch, J.M. 149

Capra, G. 137

Ferrari, L. 95

Fracchia, M.S. 12

Gallagher, T.Q. VIII, 19, 26, 31, $39,42,50,58,63,66,70,76$, 127
Hansen, M.C. VIII

Harsha, W.J. 132

Hartnick, C.J. VIII, 19, 26, 31, 39, $42,50,58,63,66,70,76,86,105$, $109,112,127$

Holinger, L.D. 1

Kakodkar, K.A. 1

Maturo, S.C. $86,105,109,112$

Modi, V.K. 90, 116, 123

Rahbar, R. 95

Rogers, D.J. 132
Schroeder Jr., J.W. 1

Setlur, J. 149

Smith, M.E. 80

Watters, K. 95

Yonker, L.M. 12 